\title{
Waste Scavenging a Problem or an Opportunity for Integrated Waste Management in Namibia: A Case of Keetmanshoop Municipality, Namibia
}

\author{
Filippus Nambuli $^{1}$, Cecil Togarepi $^{2} \&$ Albertina Shikongo $^{1}$ \\ ${ }^{1}$ Department of Integrated Environmental Science, University of Namibia, Ogongo Campus, Oshakati, Namibia \\ ${ }^{2}$ Department of Agricultural Economics and Extension, University of Namibia, Ogongo Campus, Oshakati, \\ Namibia \\ Correspondence: Filippus Nambuli, Department of Integrated Environmental Science, University of Namibia, \\ Ogongo Campus, Private Bag 5520, 15001 Oshakati, Namibia. E-mail: fnambuli@unam.na
}

Received: May 2, 2021

doi:10.5539/ep.v10n2p47
Accepted: June 4, $2021 \quad$ Online Published: June 8, 2021

URL: https://doi.org/10.5539/ep.v10n2p47

\begin{abstract}
Waste scavenging is an emerging challenge faced by many Municipalities and Local Authorities in Namibia. However, it has been neglected by authorities due to insufficient knowledge about its contribution to resource recovery and recycling. This study investigated how waste scavenging as a problem can be transformed into an opportunity for Integrated Waste Management in Namibia. The main objective of the study was to determine the socio-economic drivers as well as health implications of waste scavenging at Keetmanshoop municipal dumping site, Namibia. Using the purposive sampling method, a total of 45 waste pickers were interviewed through semistructured questionnaires. The data collected included waste pickers demographic (age, gender, marital status, and level of education), socio-economic impacts (income and diseases) from waste scavenging. The study revealed that the main drivers of waste scavenging are poverty (71.1\%) and unemployment (64.4\%). Furthermore, waste scavenging contributes significantly to waste pickers' livelihood through income generation from the sale of waste materials $(93.3 \%)$. The majority of the waste pickers $(80 \%)$, scavenge mainly for metals whereas the least target food. The study concluded that waste scavenging, although neglected, contributes significantly to the livelihoods of waste pickers and waste management in Keetmanshoop. The study recommends that waste scavenging should be regulated and integrated into the formal waste management system of the Municipality through avenues such as the formation of the waste picker's cooperatives that will be registered with the municipality and recognised through formal structures.
\end{abstract}

Keywords: dumping site, Namibia, recycling, socio-economic impacts, waste management, waste scavenging

\section{Introduction}

Waste is defined as any material which is no longer valuable to the owner and has to be discarded (Magaji \& Dakyes, 2011). Managing waste is a challenge for many developing countries due to lack of capacity, technology (Forbid, Ghogomu, Busch, \& Frey, 2011), and financial resources which are exacerbated by increased waste generation projected to rise by 5.9 billion tons per annum globally by the year 2025 (Masood \& Barlow, 2013). The increased waste generation in most towns of developing countries is a result of industrialisation, urbanisation and to some extent increase in population (Manaf, Armi, Samah, Ilyana, \& Zukki, 2009 ).

Not all waste at dump sites is useless, as some of the waste can be recycled into valuable products. This has led to many unemployed and poor members of society to scavenge for the waste for recycling, sale, or own use (Omotoso, 2017). In several developing countries including Namibia, however, this informal waste management (waste scavenging) is not recognised and is deemed illegal (Asim, Batool, \& Chaudhry, 2012). Other developing countries, however, have recognised the efforts of informal waste management strategies and have incorporated them into the formal waste management systems with huge benefits (Tirado-Soto \& Zamberlan, 2013).

Namibia is undergoing major socio-economic development which aims at transforming the country to be industrialized by the year 2030. Since independence, industrial production has significantly increased resulting in the rise of the volume of solid waste generation. The annual waste generation in Namibia is estimated to be 788 841.24 tons at the town level (Ruppel \& Ruppel-Schlichting, 2011). In addition, rapid urbanization owing to fast 
population growth has increased the amount of waste generation in cities, which poses some challenges to formal municipal solid waste management in developing countries (Kumar et al., 2009; Marshall \& Farahbakhsh, 2013). Unlike in developed countries where there are well-developed recycling systems in place, in developing countries such as Namibia, such systems do not exist. In addition, many municipalities in developing countries face many challenges such as a lack of sufficient funds, technology, and expertise to handle waste which ultimately hinders proper waste management (Manaf et al., 2009).

Namibia is faced with high inequality, poverty, and a high unemployment rate among the youth which is estimated at 33.4\% (Namibia Statistics Agency (NSA), 2018). As a result, many people migrate from rural to urban areas in search of scarce job opportunities. As a consequence, many find themselves unemployed and are forced to engage in other survival strategies such as waste scavenging to make a living (Magaji \& Dakyes, 2011).

Waste scavenging is defined as the manual sorting and picking of recyclables by waste pickers from municipal landfill sites for subsistence purposes (food, clothing, artefacts) or sale (Kimbugwe \& Ibitayo, 2014). Despite the stigma and occupational health risks associated with waste scavenging, this practice is still prevalent in many developing countries(O’ Hare, 2019). In various literature, waste pickers are generally referred to as either reclaimers, waste pickers, garbage pickers, recyclers, waste scavengers, and waste salvagers (Schenck \& Blaauw, 2011). Therefore, in this paper, the terms waste pickers and waste scavengers will be used interchangeably.

Waste scavenging for many impoverished urban communities is a matter of survival, not a choice. Various factors force people to engage in waste scavenging such as lack of employment opportunities, poverty, lack of education, and growing markets for recyclables (Majeed, Batool, Chaudhry, \& Siddique, 2017). Though waste scavenging plays an important role in waste management, in many countries, it is often neglected, unregulated, and considered illegal (Schenck \& Blaauw, 2011) and backward, unhygienic, and has no place in the modern waste management systems (Masood \& Barlow, 2013). Though neglected, waste scavenging is an important economic activity that supports about $2 \%$ of the population in developing countries (Magaji \& Dakyes, 2011). Usually, the waste pickers mainly target recyclable items such as scrap metals, waste papers, bottles, glasses, metal cans, scrap tyres, and car batteries (Rankokwane \& Gwebu, 2006; Rogerson, 2001), which are either re-used or recycled and sold either to an agent or companies or informally to generate an income (Asim et al., 2012) and for their consumption (Adeyemi, Olorunfemi, \& Adewoye, 2001).

Waste scavenging is highly a sacrificial profession as it exposes waste pickers to serious health risks and hazards, occupational health, and diseases such as food poisoning, diarrhoea, nausea, typhoid fever, cholera, dysentery, tuberculosis, anthrax, poliomyelitis, skin disorders, pneumonia and malaria (Afon, 2012; Asim et al., 2012), shorter life expectancy (Marello \& Helwege, 2018), high infant mortality, (Moreno-sanchez, Maldonado, \& Sheldon, 2004), injuries and wounds, and insect stings.

Besides health risks and hazards, in many cases, waste scavengers are subject to exploitation and discrimination by middlemen and by local and national government policies (Magaji \& Dakyes, 2011). In most developing countries, the government and the general public have a negative attitude towards waste scavengers. They are often undervalued and ignored, with a lack of consideration when formulating waste management policies. In most developing countries solid waste management has been complicated by high inequality, economic growth, urbanisation, policies, governance, cultural and socio-economic factors (Marshall \& Farahbakhsh, 2013). To date, Brazil, Indonesia, the Philippines, and Colombia have set a good example for the recognition of waste scavenging as a profession whereby it is legitimatized and given the necessary support (Medina, 2007) through the formation of cooperatives (Colombijn \& Morbidini, 2017; Paul, Arce-Jaque, Ravena, \& Villamor, 2012). Mainstreaming waste scavenging in the overall waste management policies and structures will go a long way in regularising waste scavenging and improving the livelihoods of waste pickers. This will further empower waste scavengers to diversify their livelihoods (Paul et al., 2012). Despite the potential benefits, it still, however, remains a huge challenge for many municipalities in developing countries to integrate the informal waste management sector into the municipal solid waste management systems (Paul et al., 2012; Guerrero, Maas, \& Hogland, 2013) which Keetmanshoop and other municipalities in Namibia are not immune to.

Socio-economic and health effects of waste scavenging have been studied extensively and scientifically documented in some African Countries (e.g. Nigeria, Botswana, Kenya, etc) (Afon, 2012; Rankokwane \& Gwebu, 2006; Sibanda, Obange, \& Awuor, 2017). In Namibia, few studies have attempted to investigate various aspects of waste management, for example; municipal waste management in Namibia (Hasheela, 2009); opportunities and challenges of waste management (Croset, 2014); waste management and recycling (Magen, 2010). Despite these studies, there has been no attempt in Namibia, especially in Keetmanshoop to examine the socio-economic and health implications of waste scavenging despite it being a challenge facing many municipalities in the country. To 
date, most of the contributing factors to waste scavenging in Namibia are usually generalized based on inferences from studies conducted in other African countries and elsewhere in the world. Hence, most information on waste pickers in Namibia is not documented but mainly based on anecdotal evidence especially from newspapers without facts. This makes it difficult to devise evidence-based policies that respond to the needs of informal waste pickers. It is therefore imperative to provide scientific and evidence-based information on different aspects of waste scavenging in Namibia, thus contributing to the field of waste management and provide the basis for the development of sound, effective and evidence-based policies that are responsive to the needs and plight of waste pickers. This study therefore aimed at filling this gap by examining the socio-economic drivers of waste scavenging and its associated health implications on waste pickers in Keetmanshoop in the //Kharas Region of Namibia. The objectives of the study were therefore to (i) determine the socio-economic factors that lead to waste scavenging in Keetmanshoop, (ii) determine the socio-economic and health impacts of waste scavenging towards the waste pickers livelihood (iii) determine the type of waste materials being scavenged by waste pickers and (iv) to assess the perception of waste pickers willingness to form a waste picker cooperative.

\section{Materials and Methods}

\subsection{Study Area}

The study was conducted at the Keetmanshoop municipal dumping site situated on the south-eastern side of Keetmanshoop town in the Keetmanshoop Urban Constituency, //Kharas Region (Figure.1). Keetmanshoop is the capital of the //Kharas region, which is about $500 \mathrm{~km}$ south-east of the capital Windhoek with a population of about 20,977 people (Namibia Statistics Agency, 2012) of which 19447 constitute Keetmanshoop Urban Constituency (Namibia Statistics Agency, 2014). Being the administrative centre for//Kharas Region, the town is faced with a challenge of rural-urban migration from nearby villages such as Tses, Koes, Aroab, and neighbouring farms in search of employment opportunities. The main economic activities in the town are tourism, farming, and agriculture, which produce more than 788 tons of waste per year (Namibia Statistics Agency, 2012). Employment opportunities are very scarce; as a result, the town has an unemployment rate of 27.7\% (Namibian Statistics Agency, 2015 ) while the general unemployment is $35.1 \%$ in //Kharas region, of which the youth constitute $48.6 \%$ (Namibia Statistics Agency, 2018). The main sources of waste in the town are households, supermarkets, and some industries. Medical waste from the clinics and the hospital are not dumped at the dumping site but instead, it is incinerated at the Keetmanshoop District Hospital.

The municipal landfill site in Keetmanshoop is rather an "open dump" that is unfenced. Previously, the dumpsite was fenced off by the municipality in 2015 however; the fence has since been vandalized by the communities (Benade, 2019 pers.comm.). This makes it difficult for proper management resulting in animals such as dogs and communities gaining entrance into the landfill site without any restrictions. Some of the waste scavengers have made the landfill site their residence by erecting some illegal shacks next to the landfill site. Currently, the municipality has a contract with a waste recycling company but it prohibits waste pickers in its operations yet other countries in Latin America have incorporated waste pickers in waste management and it is bearing fruits (Meira de Sousa- Dutra et al., 2018). At the moment, the municipality does not have any by-laws regulating waste scavenging; hence waste scavenging is a de facto illegal activity. Due to a lack of by-laws, there is no regulatory guidance on how waste scavengers should not operate nor are there penalties given to the waste scavengers. Furthermore, the Keetmanshoop Municipality does not have any records of waste scavengers and does not regulate them. 


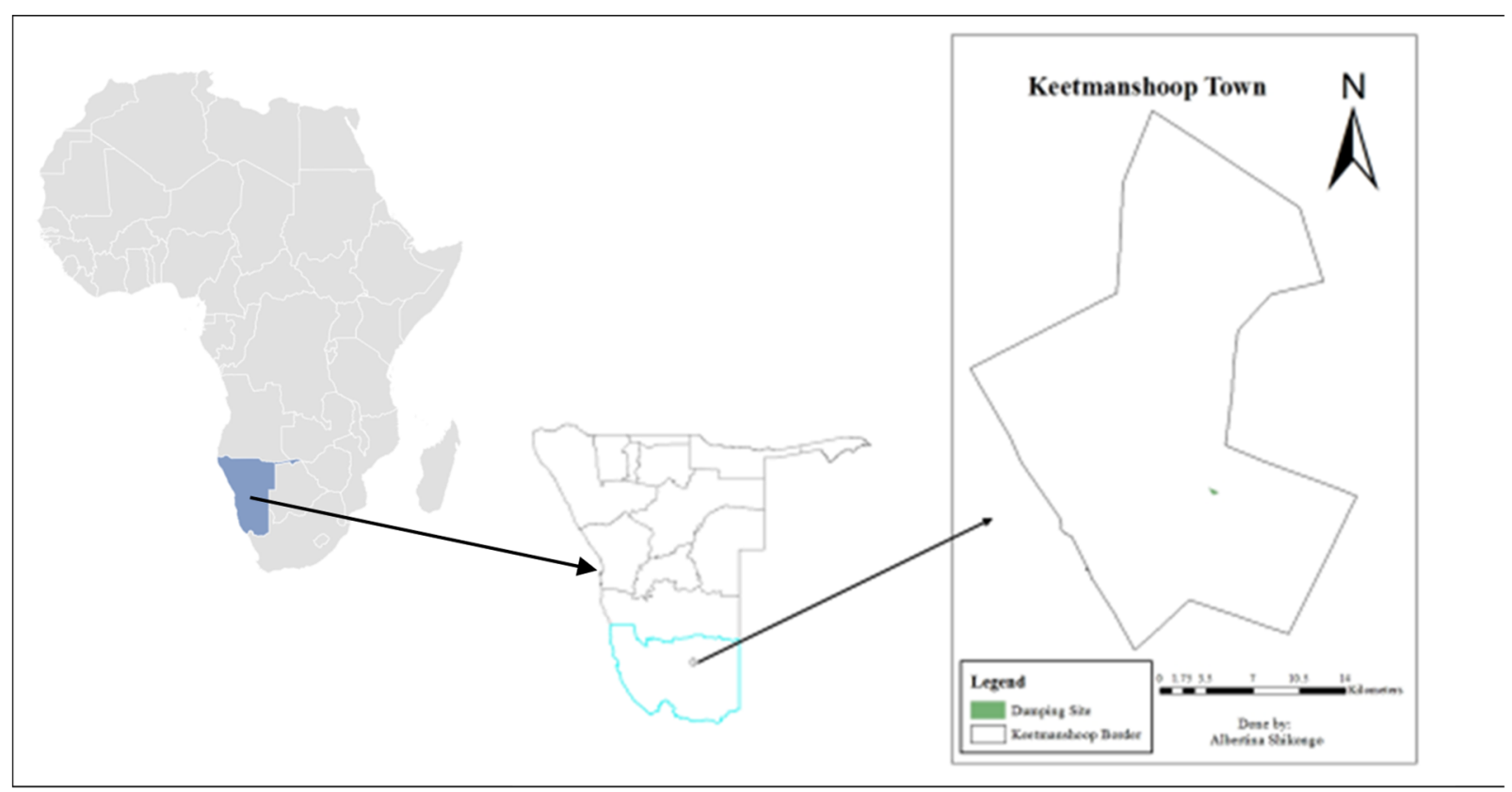

Figure 1. A map of the study area

Source: ArcGIS, 2019

\subsection{Research Design and Sampling Method}

The exact number of waste pickers in Keetmanshoop is unknown since waste scavenging in Keetmanshoop is not regulated; therefore, it was difficult to determine the appropriate sample size. Thus, exploratory and descriptive approaches were used. Exploratory research design seeks to find out the phenomenon and not necessarily provide conclusive answers but provides an understanding of the phenomenon. On the other hand, descriptive techniques provide detail and allow for defamiliarisation of the familiar and describe the existing phenomenon (Athanasou et al., 2013; Abdulraheem et al., 2018; Funmilayo et al., 2019; Gift \& Obindah, 2020). These approaches allow for qualitative and quantitative methods to be employed (Athanasou et al., 2013; Abdulraheem et al., 2018; Funmilayo et al., 2019; Gift \& Obindah, 2020). The sampling technique adopted for this study is the purposive sampling method whereby only those individuals that were identified onsite scavenging were targeted and interviewed. A total of 45 waste pickers were interviewed through a semi-structured questionnaire which was administered onsite by the researcher between June and July 2019.

\subsection{Data Collection}

Data was collected using questionnaires which were filled by the researcher through interviewing the waste pickers. Due to the diversity of ethnic groups at the dumpsite, the interview was conducted in the waste pickers' preferred language which was either English, Afrikaans, or Oshiwambo. The study utilised primary data obtained from waste pickers through questionnaire administration and physical observations while secondary sources included information from textbooks, journal articles, newspapers, and internet sources. Parameters of the questionnaire included demographic data (age, gender, marital status, education), socio-economic and health data (income earned from the sale of waste scavenged, other employment opportunities besides scavenging, diseases experienced, and general information (the type of material scavenged, market, etc). Data were collected during offloading times as well as during times when there was no offloading taking place. Offloading time is the time that the waste-filled truck arrives at the dumping site and off-load the waste. During this time, waste pickers rush to the truck to obtain waste materials. To obtain a more balanced view on waste scavenging in Keetmanshoop, the head of the waste management division at the Keetmanshoop municipality was also interviewed.

\subsection{Data Analysis}

Data collected from field surveys were analysed using descriptive statistics (crosstabs and frequencies) to get frequencies, means, and relationships between variables using the Statistical Package for the Social Sciences (SPSS) software version 21 and Microsoft Excel application. Graphical techniques were employed to present the results. 


\section{Results}

\subsection{Socio-Economic and Demographic Characteristics of Waste Pickers}

Waste scavenging in Keetmanshoop is gendered, mainly dominated by males $(77.8 \%)$, of which the majority are below the ages of 18 (28.9\%), who are supposed to be in school whereas females constitute only $22.2 \%$ (Table 1 ). In terms of marital status, the majority of waste pickers are single $(95.6 \%)$, with only $4.4 \%$ of waste pickers that are married (Table 1.). Amongst the single waste pickers, $73.3 \%$ were male, while $22.2 \%$ were female. All waste pickers had some level of education, more than half have attained primary education level $(51.1 \%)$ whereas only $40 \%$ attained secondary education level (Table 1 ).

Table 1. Socio-economic and demographic attributes of waste pickers by age at Keetmanshoop dumping site

\begin{tabular}{|c|c|c|c|c|c|c|c|c|}
\hline & & \multicolumn{6}{|c|}{ Age group } & \multirow[b]{2}{*}{ Total } \\
\hline & & below 18 & $18-24$ & $25-34$ & $35-44$ & $45-54$ & 55 and above & \\
\hline \multirow{2}{*}{ Gender } & Male & $13(92.9)$ & $3(75)$ & $9(60)$ & $9(90)$ & $1(100)$ & $0(0)$ & $35(77.8)$ \\
\hline & Female & $1(7.1)$ & $1(25)$ & $6(40)$ & $1(10)$ & $0(0)$ & $1(100)$ & $10(22.2)$ \\
\hline \multirow{3}{*}{$\begin{array}{l}\text { Level of } \\
\text { education }\end{array}$} & Primary & $9(64.3)$ & $1(25)$ & $7(46.7)$ & $5(50)$ & $0(0)$ & $1(100)$ & $23(51.1)$ \\
\hline & Secondary & $3(21.4)$ & $3(75)$ & $8(53.3)$ & $4(40)$ & $0(0)$ & $0(0)$ & $18(40)$ \\
\hline & No school attendance & $2(14.3)$ & $0(0)$ & $0(0)$ & $1(10)$ & $1(100)$ & $0(0)$ & $4(8.9)$ \\
\hline \multirow{3}{*}{ Marital Status } & Single & $14(100)$ & $4(100)$ & $15(100)$ & $8(80)$ & $1(100)$ & $1(100)$ & $43(95.6)$ \\
\hline & Married & $0(0)$ & $0(0)$ & $0(0)$ & $2(20)$ & $0(0)$ & $0(0)$ & $2(4.4)$ \\
\hline & Total & $14(31)$ & $4(9)$ & $15(33)$ & $10(22)$ & 1(2) & 1(2) & $45(100)$ \\
\hline
\end{tabular}

Note: number in brackets denotes the percentage.

\subsection{Socio-Economic Factors That Lead to Scavenging}

Various factors force people to scavenge for waste in Keetmanshoop. The major factors that contribute to waste scavenging in Keetmanshoop are poverty and unemployment constituting $71.1 \%$ and $64.4 \%$ respectively, suggesting that most people engage in waste scavenging for economic reasons. These factors which drive people to scavenge vary with age. The adults who are between the ages of 45 years and above mainly scavenge due to poverty and unemployment while the younger people between the ages of 18 years and younger mainly scavenge due to poverty. It is worth noting that other factors such as a business opportunity $(11.1 \%)$, passion for the job $(6.7 \%)$, hunger $(8.9 \%)$, cleaning the environment $(2.2 \%)$ also contribute to waste scavenging. However, interestingly about $2.2 \%$ scavenge to obtain cash which is used to buy drugs (Figure 2).

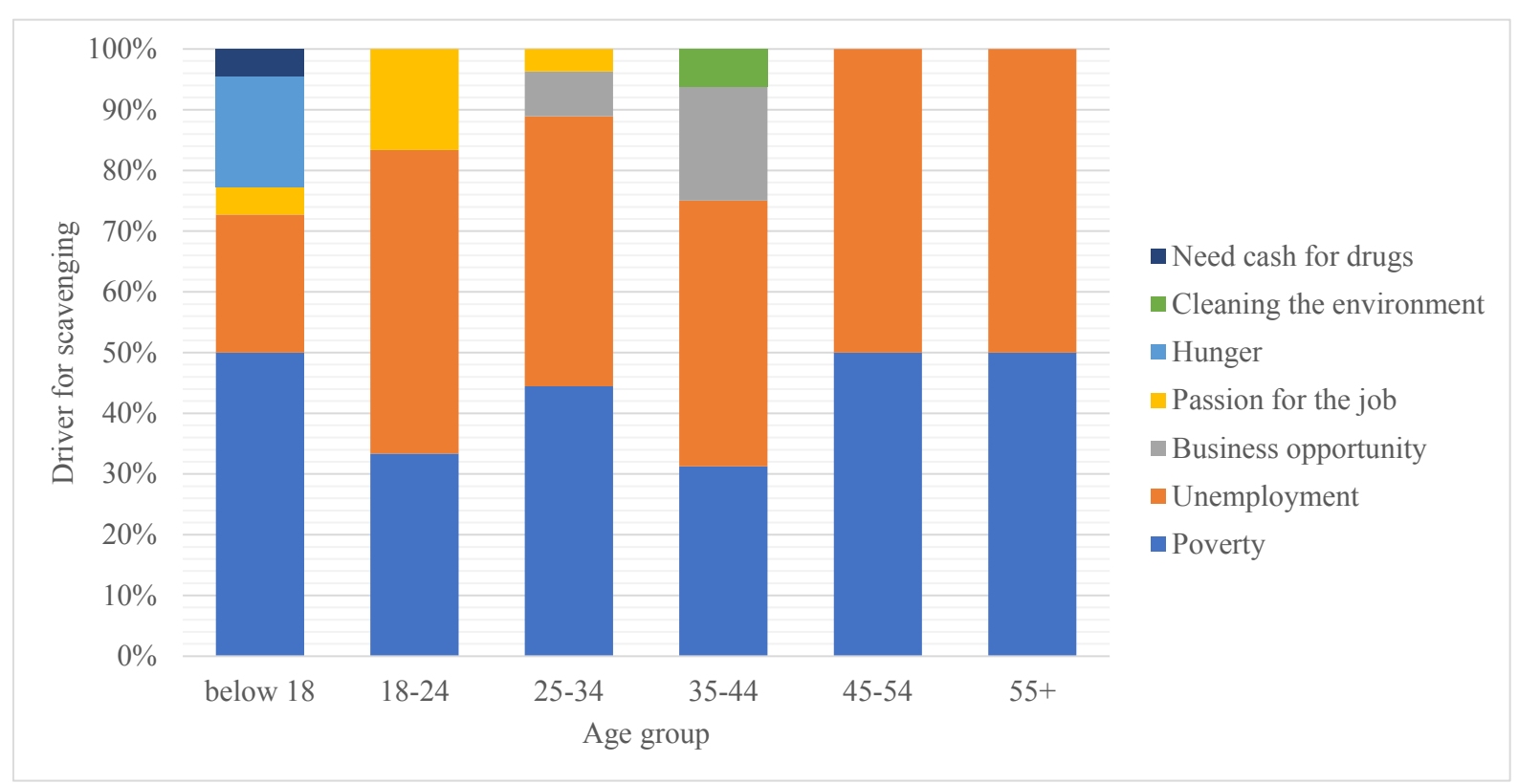

Figure 2. Socio-economic drivers for waste scavenging in Keetmanshoop 


\subsection{Socio-Economic and Health Impacts of Waste Scavenging on Waste Scavengers' Livelihoods}

Waste scavenging is a risky undertaking, which may result in occupational health and diseases due to unsafe working conditions. The study reveals that more than half of the waste scavengers $(57.8 \%)$ in Keetmanshoop did not have any pre-existing co-morbidity before they began with waste scavenging. However, after they began scavenging, $42.2 \%$ reported that they got sick (Table 2). The major diseases experienced include coughs and chest pains $(37.7 \%)$ as well as skin infections (4.4\%). Besides diseases, waste scavengers also experienced other risks such as open cuts on their body from sharp objects; due to lack of protective clothing a situation that exposes their bodies to other ailments.

Table 2. Diseases and risks experienced by waste scavengers at Keetmanshoop dumping site

\begin{tabular}{lllllllll}
\hline & & \multicolumn{7}{c}{ Age group } \\
\cline { 3 - 8 } & & below 18 & $18-24$ & $25-34$ & $35-44$ & $45-54$ & 55 and above & Total \\
\hline Got sick since started waste & Yes & $6(42.9)$ & $2(50)$ & $5(33.3)$ & $4(40)$ & $1(100)$ & $1(100)$ & $19(42.2)$ \\
scavenging & No & $8(57.1)$ & $2(50)$ & $10(66.7)$ & $6(60)$ & $0(0)$ & $0(0)$ & $26(57.8)$ \\
Reasons for continuing picking & N/A & $8(31)$ & $2(8)$ & $10(39)$ & $6(23)$ & $0(0)$ & $0(0)$ & $26(100)$ \\
waste? & Means of survival & $6(33)$ & $2(11)$ & $5(28)$ & $3(17)$ & $1(6)$ & $1(6)$ & $18(100)$ \\
& None & $4(28.6)$ & $0(0)$ & $6(40)$ & $4(40)$ & $0(0)$ & $1(100)$ & $15(33.3)$ \\
Other risks apart from diseases & Cuts on body & $10(71.4)$ & $4(100)$ & $9(60)$ & $6(60)$ & $1(100)$ & $0(0)$ & $30(66.7)$ \\
\hline
\end{tabular}

Note: Number in brackets denotes the percentage

\subsection{Types of Waste Materials Scavenged}

Waste scavengers are very smart as they target materials that are valuable or have the potential to generate a good income. Hence, the majority of waste scavengers target mainly metals $(80 \%)$, whereas one-third target clothes and bottles, and the least target food (Figure 3.). Metals especially aluminium cans have high economic value, which is sold to a recycling company in Keetmanshoop at a relatively high price compared to other items.

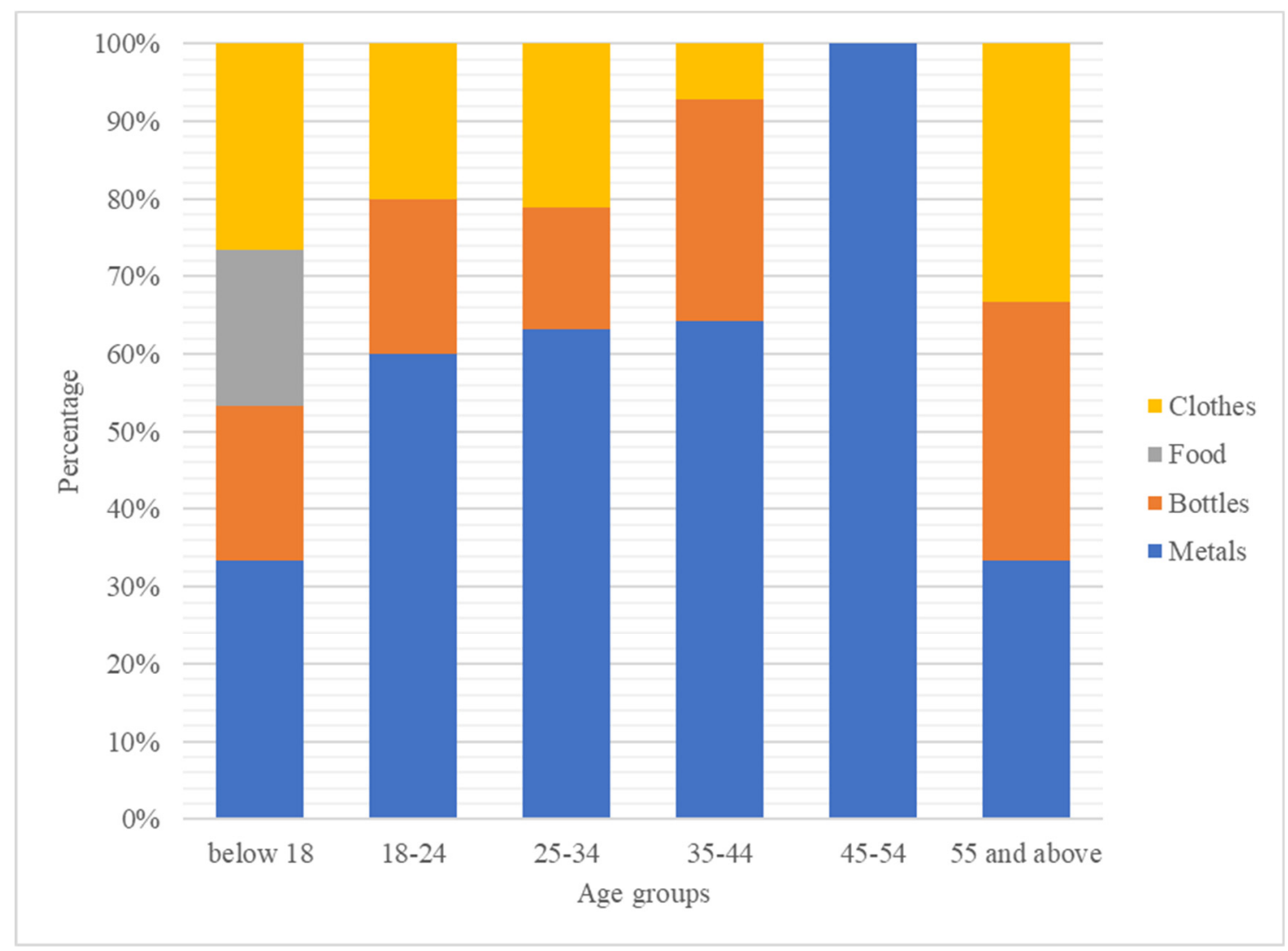

Figure 3. Main types of materials scavenged per age group 


\subsection{Average Income Generated per Day from Waste Material and Expenditure Use}

Waste scavenging is an important economic activity for the urban poor and marginalized communities, although it has been perceived as dirty. The study reveals that on average, the majority of waste scavengers (77.8\%) generate an average income of $\mathrm{N} \$ 100-500$ per day from selling metals, $60 \%$ from bottles and clothes whereas $33.3 \%$ from clothes (Table 3). This translates to $\mathrm{N} \$ 3000-\mathrm{N} \$ 15000$ per month which is significantly higher than the prescribed minimum wage of some job categories such as cleaners, security guards, and petrol attendants who are employed permanently. The income generated from the sale of recyclables is used for paying school fees, paying monthly bills, family, and self-sustenance (Table 4).

Table 3. Average income in N\$ generated per day by type of materials scavenged

\begin{tabular}{llllll}
\hline \multicolumn{5}{c}{ Average income per day from waste scavenging } \\
\cline { 3 - 6 } & & $<\mathrm{N} \$ 100$ & $\mathrm{~N} \$ 100-\mathrm{N} \$ 500$ & $\mathrm{~N} \$ 500-\mathrm{N} \$ 1000$ & Total \\
\hline Metals & Yes & $7(19.4)$ & $28(77.8)$ & $1(2.8)$ & $36(100)$ \\
Bottles & Yes & $6(40)$ & $9(60)$ & $0(0)$ & $15(100)$ \\
Food & Yes & $4(66.7)$ & $2(33.3)$ & $0(0)$ & $6(100)$ \\
Clothes & Yes & $6(40)$ & $9(60)$ & $0(0)$ & $15(100)$ \\
\hline
\end{tabular}

Note: Number in brackets denotes the percentage

Table 4. Average income in N\$ generated per day and use by age group

\begin{tabular}{|c|c|c|c|c|c|c|c|c|}
\hline & & \multicolumn{7}{|c|}{ Age group } \\
\hline & & below 18 & $18-24$ & $25-34$ & $35-44$ & $45-54$ & 55 and above & Total \\
\hline \multirow{4}{*}{$\begin{array}{l}\text { Average income from waste } \\
\text { scavenging per day }\end{array}$} & Less than N\$ 100 & $5(35.7)$ & $2(50)$ & $3(20)$ & $2(20)$ & $0(0)$ & $0(0)$ & $12(26.7)$ \\
\hline & Between N\$ $100-\mathrm{N} \$$ & $8(57.1)$ & $2(50)$ & $12(80)$ & $8(80)$ & $1(100)$ & $1(100)$ & $32(71.1)$ \\
\hline & Between N\$ $500-\mathrm{N} \$$ & $(1(7.1)$ & $0(0)$ & $0(0)$ & $0(0)$ & $0(0)$ & $0(0)$ & $1(2.2)$ \\
\hline & School fees & $0(0)$ & $0(0)$ & $1(6.7)$ & $1(10)$ & $0(0)$ & $0(0)$ & $2(4.4)$ \\
\hline \multirow{3}{*}{ Uses of income } & Pay bills & $6(42.9)$ & $1(25)$ & $4(26.7)$ & $2(20)$ & $0(0)$ & $0(0)$ & $13(28.9)$ \\
\hline & Family maintenance & $6(42.9)$ & $2(50)$ & $13(86.7)$ & $10(100)$ & $1(100)$ & $1(100)$ & $33(73.3)$ \\
\hline & Self maintenance & $5(35.7)$ & $1(25)$ & $1(6.7)$ & $0(0)$ & $0(0)$ & $0(0)$ & $7(15.6)$ \\
\hline
\end{tabular}

Note: Number in brackets denotes the percentage

3.6 Perception of Waste Scavengers on Willingness to Be Organised and Assistance Required from the Municipality

The majority of waste pickers (68.9 \%) support the idea to establish a waste pickers association (Table 5) that would perform a coordination role for waste scavengers. Despite their level of education, most waste scavengers (73.3 \%) acknowledge that waste scavenging plays an important role in waste management. Sadly, due to scarce job opportunity and low education level, about $40 \%$ depends solely on waste scavenging for their livelihood. If they had a choice, most waste scavengers $(82.2 \%)$ are eager to stop scavenging if they manage to get a job (Figure 4).

Table 5. Perception of waste scavengers on waste scavenging at Keetmanshoop dumping site

\begin{tabular}{|c|c|c|c|c|c|c|c|c|}
\hline & & \multicolumn{7}{|c|}{ Age group } \\
\hline & & below 18 & $18-24$ & $25-34$ & $35-44$ & $45-54$ & 55 and above & Total \\
\hline \multirow{2}{*}{ Want to be part of waste pickers cooperative } & Yes & $6(42.9)$ & $3(75)$ & $13(86.7)$ & $8(80)$ & $0(0)$ & $1(100)$ & $31(68.9)$ \\
\hline & No & $8(57.1)$ & $1(25)$ & $2(13.3)$ & $2(20)$ & $1(100)$ & $0(0)$ & $14(31.1)$ \\
\hline \multirow{2}{*}{ Waste scavenging plays a role in waste management } & Yes & $8(57.1)$ & $3(75)$ & $12(80)$ & $9(90)$ & $0(0)$ & $1(100)$ & $33(73.3)$ \\
\hline & No & $6(42.9)$ & $1(25)$ & $3(20)$ & $1(10)$ & $1(100)$ & $0(0)$ & $12(26.7)$ \\
\hline \multirow{2}{*}{$\begin{array}{l}\text { Would getting a good job make you to stop } \\
\text { scavenging? }\end{array}$} & Yes & $9(64.3)$ & $3(75)$ & $14(93.3)$ & $9(90)$ & $1(100)$ & $1(100)$ & $37(82.2)$ \\
\hline & No & $5(35.7)$ & $1(25)$ & $1(6.7)$ & $1(10)$ & $0(0)$ & $0(0)$ & $8(17.8)$ \\
\hline \multirow{2}{*}{$\begin{array}{l}\text { Would a learning or studying opportunity make you to } \\
\text { stop scavenging? }\end{array}$} & Yes & $3(21.4)$ & $0(0)$ & $1(6.7)$ & $0(0)$ & $0(0)$ & $0(0)$ & $4(8.9)$ \\
\hline & No & $11(78.6)$ & $4(100)$ & $14(93.3)$ & $10(100)$ & $1(100)$ & $1(100)$ & $41(91.1)$ \\
\hline \multirow{2}{*}{ Scavenging only means of livelihood } & Yes & $9(64.3)$ & $2(50)$ & $5(33.3)$ & $2(20)$ & $0(0)$ & $0(0)$ & $18(40)$ \\
\hline & No & $5(35.7)$ & $2(50)$ & $10(66.7)$ & $8(80)$ & $1(100)$ & $1(100)$ & $27(60)$ \\
\hline
\end{tabular}

Note: Number in brackets denotes the percentage 


\section{Discussion}

Waste scavenging in Keetmanshoop is gendered, mainly dominated by males $(77.8 \%)$ while males below the ages of 18 are the majority (28.9\%), who are supposed to be in school whereas females constitute only $22.2 \%$ (Table 1). These findings concur with that of (Schenck \& Blaauw, 2011) in a similar study in Pretoria, South Africa, where the majority of waste pickers were males. All females were single, this is consistent with a similar finding in South Africa where the majority of scavengers were single women (Nyathi, Olowoyo, \& Oludare, 2018) which can be due to differences in gender roles assigned to males and females in different societies. This is mainly because waste scavenging is quite stressful, highly competitive, high-risk undertaking, labour intensive, and requires a lot of energy to drag recyclables from the heap. Hence, men can withstand these harsh conditions compared to females who may not be able to cope with these conditions.

Age is another determining factor about the capability to cope with this demanding profession, no wonder young people under the age of 18 dominates this profession. The age ranged between 10-55 years with the majority being younger individuals, which is consistent with findings for countries such as South Africa (25-61 years) (Nyathi et al., 2018) and 41-50 (Schenck \& Blaauw, 2011). This is not surprising as //Kharas region is dominated by a young population of which $32 \%$ are unemployed (Namibia Statistics Agency, 2014). In addition, young people are more energetic to cope with the pressure of this demanding profession (Rankokwane \& Gwebu, 2006).

The majority of waste pickers are single (95.6\%), with only $4.4 \%$ of waste pickers that are married (Table 1.). Of the single waste pickers, $73.3 \%$ were male, while $22.2 \%$ were female. Culturally, married women, even if unemployed are taken care of by their spouses compared to single women with limited livelihood and support options. In contrast to fewer single females in the case study, studies conducted by (Nyathi et al., 2018) in South Africa indicate that the majority of the waste pickers were single women. This could indicate the hardships that single women face in society and the lack of safety nets and social capital that they can rely on for support compared to married women who get support from their spouses whose role is to provide for the family.

In terms of education, more than half of the waste scavengers only attained primary education level (51.1\%) whereas only $40 \%$ of the waste pickers attended secondary education (Table.1). Interestingly, none of the waste scavengers had any schooling at all. Most of these waste scavengers dropped out of school due to several factors including poverty. //Kharas region has the highest school dropout level of which $83 \%$ is from Keetmanshoop urban constituency where this study was conducted (Namibia Statistics Agency, 2014). The results reveal that the majority of the waste scavengers find it hard to get absorbed in the formal job market due to lack of education as most job opportunities require skilled labour. However, since about $40 \%$ of the waste scavengers have attended secondary education, indicates that they can be trained at vocational training centres to earn a trade certificate so that they can become self-employed. The study conducted by (Magaji \& Dakyes, 2011) indicates a similar trend which correlates with the findings of this study.

\subsection{Socio-Economic Factors That Lead to Scavenging}

Various factors force people to scavenge for waste in Keetmanshoop. The major factors that contribute to waste scavenging in Keetmanshoop are poverty and unemployment constituting $71.1 \%$ and $64.4 \%$ respectively while both poverty and unemployment $(68.8 \%)$ force individuals to scavenge, thus, people engage in waste scavenging for economic and financial gains (Simatele, Dlamini, \& Kubanza, 2017). Interestingly, the factors which drive people to scavenge vary with age. The adults who are between the ages of 45 years and above mainly scavenge due to poverty and unemployment while the younger people between the ages of 18 years and younger mainly scavenge due to poverty. This concurs with the finding of (Hartmann, 2018) that most waste pickers are impoverished and also with results from the Namibia Statistics Agency, (2014) that indicate that the //Kharas region had the highest unemployment rate among the uneducated youth, of which $23.9 \%$ did not complete primary education. Given that most waste pickers only had completed primary education, it is not strange that they constitute the highest number of waste scavengers at the Keetmanshoop dumping site. Poverty and lack of alternative livelihoods are not unique to Namibia, but widespread in most developing countries (Magaji \& Dakyes, 2011; Fergutz, Dias, \& Mitlin, 2011).

However, other factors such as a business opportunity (11.1\%), passion for the job (6.7\%), hunger (8.9\%), cleaning the environment $(2.2 \%)$. Unlike in other studies, this study discovered that about $(2.2 \%)$ of the waste pickers engage in scavenging to obtain money to buy drugs. Although not quite significant, it demonstrates a worrisome trend that requires further investigation. Due to a lack of formal employment (Fergutz et al., 2011; Schenck \& Blaauw, 2011), people engage in waste scavenging as a means of survival and recyclable waste for sale to make a living. 


\subsection{Socio-Economic and Health Impacts of Waste Scavenging on Waste Scavengers' Livelihoods}

Waste scavenging is a risky undertaking, which may result in occupational health and diseases due to unsafe working conditions (Simatele et al., 2017). About $42.2 \%$ of the waste scavengers reported that they got sick after they began waste scavenging (Table 2). This corresponds with the findings of a study by Cruvinel et al. (2020) in Brasilia, Brazil where $85.8 \%$ of waste pickers who worked directly at dumpsites got sick. More than half of the waste scavengers (57.8\%) in Keetmanshoop indicated that they did not have any pre-existing co-morbidity before they began with waste scavenging. The diseases experienced were skin infections (4.4\%), coughs, and chest pains $(37.7 \%)$. Lack of protective equipment and awareness on how to handle potentially risk materials from the waste exposes waste scavengers to multiple health hazards including diseases (Gutberlet \& Uddin, 2017; Simatele et al., 2017). Most of the waste scavengers at the Keetmanshoop dumping site, do not have any protective equipment such as gloves or masks which expose them to diseases. This problem is prevalent where waste scavenging is overlooked by decision-makers and not integrated formally or where there are no institutional or policy frameworks for formal integration (Simatele et al., 2017; Sandhu, Burton, \& Dedekorkut-Howes, 2017). It is therefore likely that the diseases that are experienced by waste scavengers could be attributed to the horrible and dangerous conditions waste scavenging expose them to. Furthermore, economic hardship forces waste scavengers to consume expired food, resulting in stomach infections and parasites, drink untreated water, and lack of proper sanitation and healthcare are also contributing factors (Cruvinel et al., 2020). Food poisoning may cause diarrhoea, parasite infection, and nausea (Afon, 2012; Giusti, 2009) as well as respiratory disorders and allergies (Ravindra, Kaur, \& Mor, 2016). Household waste containing organic materials often attracts rats, cockroaches, which are also sources of vector-borne diseases that can be transmitted to humans (Gutberlet \& Uddin, 2017).

Besides diseases, waste scavengers also experienced other risks such as open cuts on their body from sharp objects, due to lack of protective clothing a situation that exposes their bodies to other ailments. Afon (2012) reported that most waste pickers are vulnerable to insect stings, wounds from sharp objects due to manual sorting of waste materials. If there was a choice, all waste scavengers indicated that they would stop waste scavenging, however, due to poverty and unemployment; they have no choice but to continue scavenging as a means of survival (Table 2). These findings suggest that waste pickers are highly vulnerable and at greater risk of exposure to diseases in comparison to the general population due to the hardships they experience such as poor working conditions. Despite the problems, waste scavengers face such as social, health and environmental, they are willing to continue with the activities (Sasaki, Araki, Tambunan, \& Prasadja, 2014). This shows a lack of alternative livelihoods options and it was found out that the average household income of waste scavengers in Jakarta in 2013 was equivalent to the minimum wage at that time (Sasaki et al., 2014) although vacancies will be limited in other trades thus waste scavenging becomes the only option. To minimise the health risks and other dangers associated with it, integrating informal waste scavenging into the formal waste management sector has been suggested as a panacea in other countries (Thirarattanasunthon, Siriwong, Robson, \& Borjan, 2012).

\subsection{Types of Waste Materials Scavenged}

The majority of waste scavengers target mainly metals $(80 \%)$, one-third of the respondents target clothes and bottles whereas the least target food (Figure 3.). Metals especially aluminium cans have high economic value, which is sold to a recycling company in Keetmanshoop at a relatively high price compared to other items. Hence, most waste scavengers are targeting metals. Furthermore, there is a market for metals as they can easily sell to a recycling company, hence the waste scavengers do not have to struggle for customers as they already have a buyer. A study conducted by Rankokwane \& Gwebu, (2006) in Gaborone, Botswana indicates that most waste scavengers target similar materials like the ones revealed by our study. The study suggests that waste scavengers are targeting items with high utility value, for instance, those that are recyclable or reusable materials that can be sold to generate an income (Figure 3).

\subsection{Average Income Generated per Day from Waste Material and Expenditure Use}

The study reveals that the majority of waste scavengers (77.8\%) generate an average income of N\$ 100-500 per day from selling metals, $60 \%$ from bottles and clothes, and 33.3\% from clothes (Table 3). Although this income seems inadequate, it is substantial to cater for the needs of waste pickers and on average relatively higher than the minimum wage for some low ranking employees employed in Government on a full-time basis such as cleaners, security guards, petrol attendants, etc. This study demonstrated that waste scavenging contributes significantly to the livelihood of waste scavengers in Keetmanshoop, despite being ignored by authorities perhaps due to lack of evidence.

The income generated from the sale of recyclables is used for paying school fees, paying monthly bills, family, and self-sustenance (Table 4). The majority of the waste scavengers earn between N\$100-N\$500 per day (71\%) 
which can translate to $\mathrm{N} \$ 3000$ - N\$15000 per month which some people who have permanent jobs (e.g. farm workers, domestic workers, petrol attendants, cleaners, security guards and many other government employees) are not even earning. This corroborates with findings in Indonesia where waste pickers' average income was equivalent to the minimum wage (Sasaki et al., 2014). A study conducted by Noel (2010) in Haiti, indicates that waste scavengers who dominate the informal sector generate an income relatively higher than those in the formal sector. The case of Keetmanshoop demonstrates that waste scavenging has a positive socio-economic impact on waste scavengers' livelihood and family maintenance which corroborates with the findings from South Africa in Johannesburg (Simatele et al., 2017). Thus waste scavenging directly provides income for the poor in society and the recycling activity has the potential to contribute to the economy and livelihoods (Navarrete-Hernandez \& Navarrete-Hernandez, 2018; (Botello-Álvarez, Rivas-García, Fausto-Castro, Estrada-Baltazar, \& GomezGonzalez, 2018). The contribution of informal waste picking cannot be over-emphasised for example, in South Africa, the participation of informal waste pickers has put the recycling economy on the same level as several developed countries (Godfrey \& Oelofse, 2017). Further, waste scavenging has been shown to contribute to sustainable development, reducing pollution as well as increase the useful life of landfills (Navarrete-Hernandez \& Navarrete-Hernandez, 2018; Fergutz et al., 2011; Colombijn \& Morbidini, 2017; Paul et al., 2012) and reduce dumped waste by up to $20 \%$ (Fergutz et al., 2011). In Jakarta, Indonesia, waste scavengers were estimated to collect on average about 100 kilograms per day translating to between $2.8-7.5 \%$ of all waste transported to the dump site (Sasaki \& Araki, 2014). The expenditure of the income generated indicates that it is used for necessities such as family maintenance and paying bills which shows the importance of waste scavenging to livelihoods. Thus, the benefits accruing to the waste scavengers and the economy in general when they are integrated into the formal municipal solid waste management systems are quite significant. For example, in the Philippines where formal business enterprises were registered for waste pickers associations, and integrated into the municipal solid waste management programmes, the waste scavengers were empowered to diversify their livelihoods (Paul et al., 2012). Moreover, there have to be concerted efforts to remove barriers to integration notably repressive policy, unhygienic waste collection methods (Oguntoyinbo, 2012), and governance structures that are not conducive for inclusion.

\subsection{Perception of Waste Scavengers on Willingness to Be Organised and Assistance Required from the Municipality}

The majority of waste pickers (68.9 \%) support the idea to establish a waste pickers association (Table 5) that would coordinate waste picking activities as well as take care of the welfare of the waste pickers (Fergutz et al., 2011). This shows that waste pickers are eager to be formally regulated to ensure that more benefits can be accrued from the activities. Despite the willingness for waste scavengers to be formally integrated, the only obstacle to this aspect is the legislation, which needs to recognise waste scavengers as important role players in waste management. Currently, the Waste Management and Pollution Control Bill is still under discussion. Hence, it could be important for this Bill to recognise the role of scavengers. It is also important to note that despite their level of education, most waste scavengers (73.3\%) acknowledge that waste scavenging plays an important role in waste management. Most waste scavengers $(82.2 \%)$ indicate that they will stop scavenging if they manage to get a job. Integrating waste scavenging into formal waste management systems would present opportunities for improved waste management and improved livelihoods due to formalisation. The results also show that $40 \%$ of the respondents depend solely on waste scavenging without any other means of irking a living. Thus this finding adds the weight to explore strategies for integrating waste scavenging into formal waste management which would greatly improve the livelihoods and working conditions of the waste scavenging (Dias, 2016).

The waste scavengers indicated that they would like the municipality to support them with employment (73.3\%) and transport to the dumping site (8.9\%) while $11.1 \%$ did not need anything from the municipality (Figure 4). Municipalities were often found to not recognise the importance of waste pickers and were deemed illegal in many Latin American countries (Fergutz et al., 2011) which is the case in Keetmanshoop and other cities in Southern Africa. These results indicate that poverty and unemployment are the major drivers for waste scavenging in Keetmanshoop. Hence, most waste scavengers would like to be given employment opportunities to move them out of poverty thus employment alternatives elsewhere would reduce participation in waste scavenging because it is frowned upon. However, should the waste scavenging be integrated into formal waste management systems, then most of these scavengers would feel that their work is important and it would not be viewed as a demeaning job. This would further improve the benefits from waste scavenging and contribution to waste management, as well as getting better prices for recycled goods and improved working conditions (Simatele et al., 2017; Fergutz et al., 2011) for example sorting of waste can start at household level so that the waste scavengers will be able to separate the material easily without the risk of injury and other hazards. Adopting and adapting frameworks that have been proposed and implemented elsewhere would be a starting point to integrate informal waste picking into formal waste management operations of the municipality in Keetmanshoop, see (Masood \& Barlow, 2013; 
Marshall \& Farahbakhsh, 2013).

\section{Conclusions and Policy Implications}

The study concludes that poverty and unemployment are the biggest drivers of waste scavenging in Keetmanshoop. Furthermore, the study found that waste scavenging, although quite neglected contributes significantly to waste scavengers' livelihood and provides employment for the poor in society which presents an opportunity for formalisation and improved incomes. In addition, the provision of alternative livelihoods elsewhere would reduce waste scavenging. Owing to the health risks associated with waste scavenging, the study found the working conditions of waste scavenging deplorable exposing them to hazards and diseases. The study concludes that Keetmanshoop municipality and by extension, Namibia do not have any legal frameworks that regulate waste scavenging. This situation makes waste scavenging illegal in Namibia yet it contributes significantly to waste scavengers' livelihood and waste management in general. Therefore, the study recommends that the Waste Management and Pollution Control Bill should recognise waste scavengers as important role players in waste management. This would then enable municipalities and by extension, Keetmanshoop municipality to enact bylaws that allow waste scavengers to be integrated into the formal waste management system, registered and coordinated through waste scavenging associations that will give them legal rights and labour protection. This would allow waste scavengers to have access to environmental, health, and safety education to take necessary precautions whilst scavenging for waste. Once formalised, waste scavengers can contribute meaningfully to the local economies in which they operate. This study discovered that waste scavenging is not necessarily a problem but rather an opportunity that can be capitalised on by the municipalities to cut costs and recycle waste that can be beneficial for employment creation once formalised.

\section{References}

Abdulraheem, A. F. O., Olalekan, R. M., \& Abasiekong, E. M. (2018). Mother and father adolescent relationships and substance use in the Niger Delta: a case study of twenty-five (25) communities in Yenagoa local government of Bayelsa State, Nigeria. Sociol Int J., 2(6), 541-548.

Adeyemi, A. S., Olorunfemi, J. F., \& Adewoye, T. O. (2001). Waste scavenging in Third World cities: A case study in Ilorin, Nigeria. Environmentalist, 21(2), 93-96. https://doi.org/10.1023/A:1010655623324

Afon, A. (2012). A survey of operational characteristics, socioeconomic and health effects of scavenging activity in Lagos, Nigeria. Waste Management and Research, 30(7), 664-671. https://doi.org/10.1177/0734242X12444894

Asim, M., Batool, S. A., \& Chaudhry, M. N. (2012). Scavengers and their role in the recycling of waste in Southwestern Lahore. Resources, Conservation and Recycling, 58, 152-162. https://doi.org/10.1016/j.resconrec.2011.10.013

Athanasou, J. A., Di Fabio, A., Elias, M. J., Ferreira, R., Gitchel, W. D., Jansen, J. D., ... Watson, M. (2013). Complete your thesis or dissertation successfully: Practical guidelines Edited by JG (Kobus) Maree. 70218.

Botello-Álvarez, J. E., Rivas-García, P., Fausto-Castro, L., Estrada-Baltazar, A., \& Gomez-Gonzalez, R. (2018). Informal collection, recycling and export of valuable waste as transcendent factor in the municipal solid waste management: A Latin-American reality. Journal of Cleaner Production, 182, 485-495. https://doi.org/10.1016/j.jclepro.2018.02.065

Colombijn, F., \& Morbidini, M. (2017). Pros and cons of the formation of waste-pickers' cooperatives: a comparison between Brazil and Indonesia. Decision, 44(2), 91-101. https://doi.org/10.1007/s40622-0170149-5

Croset, E. (2014). Opportunities and challenges of a Sustainable Solid Waste Management in Tsumeb, Namibia.

Cruvinel, V. R. N., Zolnikov, T. R., Takashi Obara, M., Oliveira, V. T. L. de, Vianna, E. N., Santos, F. S. G. do, ... Scott, J. A. (2020). Vector-borne diseases in waste pickers in Brasilia, Brazil. Waste Management, 105, 223 232. https://doi.org/10.1016/j.wasman.2020.02.001

Dias, S. M. (2016). Waste pickers and cities. Environment and Urbanization, 28(2), 375-390. https://doi.org/10.1177/0956247816657302

Fergutz, O., Dias, S., \& Mitlin, D. (2011). Developing urban waste management in brazil with waste picker organizations. Environment and Urbanization, 23(2), 597-608. https://doi.org/10.1177/0956247811418742

Forbid, G. T., Ghogomu, J. N., Busch, G., \& Frey, R. (2011). Open waste burning in Cameroonian cities: An environmental impact analysis. Environmentalist, 31(3), 254-262. https://doi.org/10.1007/s10669-011-9330- 
0

Funmilayo A. A, Robert O. T, Olalekan R. M, Okoyen E, Tuebi M (2019). A study of the context of adolescent substance use and patterns of use in Yenagoa local government, Bayelsa State, Nigeria. MOJ Addiction Medicine and Therapy, 6(1), 25-32.

Gift, R. A., \& Obindah, F. (2020). Examining the influence of motivation on organizational productivity in Bayelsa state private hospitals. Open Access Journal of Science, 4(3), 94-108.

Giusti, L. (2009). A review of waste management practices and their impact on human health. Waste Management, 29(8), 2227-2239. https://doi.org/10.1016/j.wasman.2009.03.028

Godfrey, L., \& Oelofse, S. (2017). Historical review of waste management and recycling in South Africa. Resources, 6(4), 1-11. https://doi.org/10.3390/resources6040057

Guerrero, L. A., Maas, G., \& Hogland, W. (2013). Solid waste management challenges for cities in developing countries. Waste Management, 33(1), 220-232. https://doi.org/10.1016/j.wasman.2012.09.008

Gutberlet, J., \& Uddin, S. M. N. (2017). Household waste and health risks affecting waste pickers and the environment in low- and middle-income countries. International Journal of Occupational and Environmental Health, 23(4), 299-310. https://doi.org/10.1080/10773525.2018.1484996

Hartmann, C. (2018). Waste picker livelihoods and inclusive neoliberal municipal solid waste management policies: The case of the La Chureca garbage dump site in Managua, Nicaragua. Waste Management, 71, 565577. https://doi.org/10.1016/j.wasman.2017.10.008

Hasheela, R. (2009). Municipal Waste Management in Namibia : The Windhoek Case Study Universidad Azteca Municipal Waste Management in Namibia: The Windhoek Case Study Universidad Azteca. Waste Management, (October).

Kimbugwe, E., \& Ibitayo, O. O. (2014). Analysis of characteristics, activities, and exposure to vermin of human landfill scavengers in a developing nation. Environment Systems and Decisions, 34(2), 358-365. https://doi.org/10.1007/s10669-013-9466-1

Kumar, S., Bhattacharyya, J. K., Vaidya, A. N., Chakrabarti, T., Devotta, S., \& Akolkar, A. B. (2009). Assessment of the status of municipal solid waste management in metro cities, state capitals, class I cities, and class II towns in India: An insight. Waste Management, 29(2), 883-895. https://doi.org/10.1016/j.wasman.2008.04.011

Magaji, J. Y., \& Dakyes, S. P. (2011). An Assessment of Socio-Economic Impact of Waste Scavenging as a means of Poverty Alleviation in Gwagwalada, Abuja. Confluence Journal of Environmental Studies, 11(January), 42-56.

Magen, Y. (2010). Waste Management and Recycling Study in Namibia: Case Study of Keetmanshoop and Ondangwa.

Majeed, A., Batool, S. A., Chaudhry, M. N., \& Siddique, R. A. (2017). Scavenging demeanor in Bahawalpur, Pakistan: social and health perspective. Journal of Material Cycles and Waste Management, 19(2), 815-826. https://doi.org/10.1007/s10163-016-0483-2

Manaf, L. A., Samah, M. A. A., \& Zukki, N. I. M. (2009). Municipal solid waste management in Malaysia: Practices and challenges. Waste Management, 2902-2906. https://doi.org/10.1016/j.wasman.2008.07.015

Marello, M., \& Helwege, A. (2018). Solid Waste Management and Social Inclusion of Wastepickers: Opportunities and Challenges. Latin American Perspectives, 45(1), 108-129. https://doi.org/10.1177/0094582X17726083

Marshall, R. E., \& Farahbakhsh, K. (2013). Systems approaches to integrated solid waste management in developing countries. Waste Management, 33(4), 988-1003. https://doi.org/10.1016/j.wasman.2012.12.023

Masood, M., \& Barlow, C. Y. (2013). Framework for integration of informal waste management sector with the formal sector in Pakistan. Waste Management and Research, 31(10 SUPPL.), 93-105. https://doi.org/10.1177/0734242X13499811

Medina, M. (2007). Waste picker cooperatives in developing countries. Membership Based Organizations of the Poor, 105-121. https://doi.org/10.4324/9780203934074

Meira de Sousa Dutra, R., Harue Yamane, L., \& Ribeiro Siman, R. (2018). Influence of the expansion of the selective collection in the sorting infrastructure of waste pickers' organizations: A case study of 16 Brazilian 
cities. Waste Management, 77, 50-58. https://doi.org/10.1016/j.wasman.2018.05.009

Moreno-sanchez, R., Maldonado, J. H., \& Sheldon, I. (2004). The role of informal waste-pickers in a dynamic model of solid-waste disposal and recycling in developing countries. (February), 1-52.

Namibia Statistics Agency. (2012). Poverty Dynamics in Namibia: A comparative study using the 1993/94, 2003/04 and the 2009/10 NHIES surveys. Namibia Statistic Agency, Windhoek.

Namibia Statistics Agency. (2014). 2011 Population and Housing Census.//Kharas Region Profile. Namibia Statistic Agency, Windhoek.

Namibia Statistics Agency (NSA). (2018). Namibia household income and expenditure survey 2015/2016 report. 1-132. Namibia Statistic Agency, Windhoek.

Namibian Statistics Agency. (2015). The Namibia Labour Force Survey 2014 Report. 1-102.Namibia Statistic Agency, Windhoek.

Navarrete-Hernandez, P., \& Navarrete-Hernandez, N. (2018). Unleashing Waste-Pickers' Potential: Supporting Recycling Cooperatives in Santiago de Chile. World Development, 101, 293-310. https://doi.org/10.1016/j.worlddev.2017.08.016

Noel, C. (2010). Solid waste workers and livelihood strategies in Greater Port-au-Prince, Haiti. Waste Management, 30(6), 1138-1148. https://doi.org/10.1016/j.wasman.2010.01.029

Nyathi, S., Olowoyo, J. O., \& Oludare, A. (2018). Perception of Scavengers and Occupational Health Hazards Associated with Scavenging from a Waste Dumpsite in Pretoria, South Africa. Journal of Environmental and Public Health, 2018. https://doi.org/10.1155/2018/9458156

O' Hare, P. (2019). 'The landfill has always borne fruit': precarity, formalisation and dispossession among Uruguay's waste pickers. Dialectical Anthropology, 43(1), 31-44. https://doi.org/10.1007/s10624-018-95336

Oguntoyinbo, O. O. (2012). Informal waste management system in Nigeria and barriers to an inclusive modern waste management system: A review. Public Health, 126(5), 441-447. https://doi.org/10.1016/j.puhe.2012.01.030

Omotoso, K. O. (2017). Informal waste recycling activities: Implications for livelihood and health. African Journal of Science, Technology, Innovation and Development, 9(6), 785-793. https://doi.org/10.1080/20421338.2017.1380584

Paul, J. G., Arce-Jaque, J., Ravena, N., \& Villamor, S. P. (2012). Integration of the informal sector into municipal solid waste management in the Philippines - What does it need? Waste Management, 32(11), 2018-2028. https://doi.org/10.1016/j.wasman.2012.05.026

Rankokwane, B., \& Gwebu, T. D. (2006). Characteristics, threats and opportunities of landfill scavenging: The case of Gaborone-Botswana. GeoJournal, 65(3), 151-163. https://doi.org/10.1007/s10708-005-3122-3

Ravindra, K., Kaur, K., \& Mor, S. (2016). Occupational exposure to the municipal solid waste workers in Chandigarh, India. Waste Management and Research, 34(11), 1192-1195. https://doi.org/10.1177/0734242X16665913

Rogerson, C. M. (2001). The waste sector and informal entrepreneurship in developing world cities. Urban Forum, 12(2), 247-259. https://doi.org/10.1007/s12132-001-0018-2

Ruppel, O., \& Ruppel-Schlichting (Eds.). (2011). Environmental Law and Policy in Namibia (1st ed.). Windhoek: Hans Seidel Foundation.

Sandhu, K., Burton, P., \& Dedekorkut-Howes, A. (2017). Between hype and veracity; privatization of municipal solid waste management and its impacts on the informal waste sector. Waste Management, 59, 545-556. https://doi.org/10.1016/j.wasman.2016.10.012

Sasaki, S., \& Araki, T. (2014). Estimating the possible range of recycling rates achieved by dump waste pickers: The case of Bantar Gebang in Indonesia. Waste Management and Research, 32(6), 474-481. https://doi.org/10.1177/0734242X14535651

Sasaki, S., Araki, T., Tambunan, A. H., \& Prasadja, H. (2014). Household income, living and working conditions of dumpsite waste pickers in Bantar Gebang: Toward integrated waste management in Indonesia. Resources, Conservation and Recycling, 89, 11-21. https://doi.org/10.1016/j.resconrec.2014.05.006

Schenck, R., \& Blaauw, P. F. (2011). The Work and Lives of Street Waste Pickers in Pretoria-A Case Study of 
Recycling in South Africa's Urban Informal Economy. Urban Forum, 22(4), 411-430. https://doi.org/10.1007/s12132-011-9125-x

Sibanda, L. K., Obange, N., \& Awuor, F. O. (2017). Challenges of Solid Waste Management in Kisumu, Kenya. Urban Forum, 28(4), 387-402. https://doi.org/10.1007/s12132-017-9316-1

Simatele, D. M., Dlamini, S., \& Kubanza, N. S. (2017). From informality to formality: Perspectives on the challenges of integrating solid waste management into the urban development and planning policy in

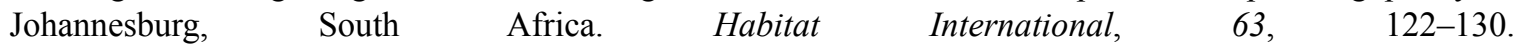
https://doi.org/10.1016/j.habitatint.2017.03.018

Thirarattanasunthon, P., Siriwong, W., Robson, M., \& Borjan, M. (2012). Health risk reduction behaviors model for scavengers exposed to solid waste in municipal dump sites in Nakhon Ratchasima Province, Thailand. Risk Management and Healthcare Policy, 5, 97-104. https://doi.org/10.2147/RMHP.S30707

Tirado-Soto, M. M., \& Zamberlan, F. L. (2013). Networks of recyclable material waste-pickers cooperatives: An alternative for the solid waste management in the city of Rio de Janeiro. Waste Management, 33(4), 10041012. https://doi.org/10.1016/j.wasman.2012.09.025

\section{Copyrights}

Copyright for this article is retained by the author(s), with first publication rights granted to the journal.

This is an open-access article distributed under the terms and conditions of the Creative Commons Attribution license (http://creativecommons.org/licenses/by/4.0/). 